\title{
Development of PCR based approach to detect potential mosaicism in porcine embryos
}

\author{
Jongki Cho ${ }^{1,2}$, Kyungjun $\mathrm{Uh}^{1,3}$, Junghyun Ryu ${ }^{1,4}$, Xun Fang ${ }^{2}$, Seonggyu Bang ${ }^{2}$ and Kiho Lee ${ }^{1,3, *}$ \\ ${ }^{1}$ Department of Animal and Poultry Sciences, Virginia Tech, Blacksburg, VA, 24061, USA \\ ${ }^{2}$ College of Veterinary Medicine, Chungnam National University, Daejeon 34134, Korea \\ ${ }^{3}$ Division of Animal Science, University of Missouri, Columbia, MO, 65211, USA \\ ${ }^{4}$ Division of Reproductive \& Developmental Sciences, Oregon Health \& Science University, Beaverton, OR, 97006, USA
}

Received November 24, 2020

Revised December 9, 2020

Accepted December 11, 2020

*Correspondence

Kiho Lee

E-mail: kiholee@missouri.edu

ORCID

https://orcid.org/0000-0003-1548-0513

\begin{abstract}
Direct injection of genome editing tools such as CRISPR/Cas9 system into developing embryos has been widely used to generate genetically engineered pigs. The approach allows us to produce pigs carrying targeted modifications at high efficiency without having to apply somatic cell nuclear transfer. However, the targeted modifications during embryogenesis often result in mosaicism, which causes issues in phenotyping founder animals and establishing a group of pigs carrying intended modifications. This study was aimed to establish a genomic PCR and sequencing system of a single blastomere in the four-cell embryos to detect potential mosaicism. We performed genomic PCR in four individual blastomeres from four-cell embryos. We successfully amplified target genomic region from single blastomeres of 4-cell stage embryo by PCR. Sanger sequencing of the PCR amplicons obtained from the blastomeres suggested that PCR-based genotyping of single blastomere was a feasible method to determine mutation type generated by genome editing technology such as CRISPR/Cas9 in early stage embryos. In conclusion, we successfully genotyped single blastomeres in a single 4-cell stage embryo to detect potential mosaicism in porcine embryos. Our approach offers a simple platform that can be used to screen the prevalence of mosaicism from designed CRISPR/Cas9 systems.
\end{abstract}

Keywords: blastomere, CRISPR/Cas9, gPCR, mosaicism, pig

\section{INTRODUCTION}

With the recent development of genetic scissors such as Zing Finger Nucleases (ZFN), Transcription ActivatorLike Effector Nucleases (TALEN), and Clustered Regularly Interspaced Short Palindromic Repeats (CRISPR)/Cas9, scientists are increasingly turning to these methods for generating transgenic organisms (Hauschild et al., 2011; Lutz et al., 2013; Sander and Joung, 2014). In particular, CRISPR/Cas9 system has been successful in introducing targeted modifications to the genome of different species with relatively low manufacturing cost and greater efficiency (Albadri et al., 2017; Ma et al., 2017; Cho et al., 2018a; Tian et al., 2018; García-Tuñón et al., 2020).

Pigs are physiologically and anatomically similar to humans, making them suitable for a candidate species for xenotransplantation. Other advantages of pigs as an animal model include relatively short gestation periods, high litter size, highly developed embryo micromanipulation system, and the possibility of artificial insemination 
(Ji et al., 2017; Lee et al., 2017; Cho et al., 2018b; Choi and Lee, 2019). During the last 20 years, genetically engineered (GE) pigs have been mainly produced through manipulating genes in the somatic cells, followed by somatic cell nuclear transfer (SCNT) (Dai et al., 2002; Lai et al., 2002; Choi et al., 2017; Jeon and Rho, 2020). Although successful, GE pigs produced via SCNT often present health complications (Carter et al., 2002; Piedrahita et al., 2004; Lee et al., 2005). Alternatively, direct injection of genome editing tools such as CRISPR/Cas9 system into developing embryos can introduce targeted modifications. GE pigs produced via direct injection of CRISPR/Cas9 system do not possess health complications at birth; however, the pigs may carry more than two alleles if targeted modifications occur after cell division. The mosaicism is considered to be a shortcoming of the approach because the phenotype of mosaic pigs often does not represent targeted modifications and the genotype of progeny derived from the mosaic pigs is difficult to predict.

The frequency of mosaicism is difficult to assess because capturing all alleles from developing embryos is extremely challenging. Establishing an effective system to detect the frequency of mosaicism will assist us to design CRISPR/Cas9 systems with minimal mosaicism. Typically, genomic PCR followed by sequencing is performed to detect potential mosaicism using blastocysts (Hirata et al., 2019). It is easier to conduct the PCR analysis using blastocysts because sufficient amount of genetic content can be obtained. However, PCR amplification of genomic DNA from blastocysts will not be able to calculate the degree of mosaicism and detect all possible alleles as PCR amplifications can be biased from a pool of genomic DNA. Single cell sequencing approach may be used to detect the level of mosaicism in blastocysts; however, cost and labor associated with the analysis are extensive.

In this study, we attempted to develop a simplified method to identify genomic information of 4-cell stage embryos by genotyping single blastomeres in the embryos. Specifically, we amplified and sequenced genomic region of TET1 gene from single blastomeres of 4-cell stage embryos to verify the feasibility of detecting mosaicism in early stage embryos. Our procedure will greatly benefit efforts to prevent mosaicism when engineering the genome using CRISRP/Cas9.

\section{MATERIALS AND METHODS}

Experiments of this study including in vitro embryo production and genotyping, were conducted based on our previous reports (Lei et al., 2016; Ryu and Lee, 2017; Uh et al., 2020). All chemicals were purchased from SigmaAldrich (St. Louis, MO, USA), unless otherwise stated.

\section{In vitro maturation of pig oocytes}

Sow ovaries obtained from a local abattoir were transported to the laboratory and washed with DPBS. Oocytes were aspirated from the ovaries using an 18-guage needle attached to syringes. Aspirates were washed with TLHepes medium three times and placed in petri dishes. Cumulus-oocyte complexes (COCs) with evenly granulated cytoplasm and intact surrounding cumulus cells were collected using a finely drawn glass capillary pipet under a microscope. Approximately 50 COCs were placed in a single well of 4-well dishes containing maturation medium (TCM-199 supplemented with $3.05 \mathrm{mM}$ glucose, $0.91 \mathrm{mM}$ sodium pyruvate, $0.57 \mathrm{mM}$ cysteine, $10 \mathrm{ng} / \mathrm{mL}$ epidermal growth factor (EGF), $0.5 \mu \mathrm{g} / \mathrm{mL}$ luteinizing hormone (LH), $0.5 \mu \mathrm{g} / \mathrm{mL}$ follicle stimulating hormone (FSH), $10 \mathrm{ng} / \mathrm{mL}$ gentamicin, and $0.1 \%$ polyvinyl alcohol (PVA); $\mathrm{pH} 7.4$ ), and incubated for $42-44 \mathrm{~h}$ at $38.5^{\circ} \mathrm{C}, 5 \% \mathrm{CO}_{2}$, and $100 \%$ humidity.

\section{In vitro fertilization of pig oocytes}

The COCs incubated in maturation medium were placed in a $1.5 \mathrm{~mL}$ centrifuge tube containing denuding medium (0.3 M mannitol, 0.001\% BSA, 0.03\% hyaluronidase, 5\% TL-Hepes medium in distilled water; $\mathrm{pH}$ 7.4), and then the cumulus cells were removed by vortexing. Oocytes with a polar body were collected in manipulation medium (TCM-199 supplemented with $0.6 \mathrm{mM} \mathrm{NaHCO} 3,2.9 \mathrm{mM}$ Hepes, $30 \mathrm{mM} \mathrm{NaCl}, 10 \mathrm{ng} / \mathrm{mL}$ gentamicin, and $3 \mathrm{mg} / \mathrm{mL}$ bovine serum albumin [BSA]) and placed in $50 \mu \mathrm{L}$ droplets of fertilization medium (modified Tris-buffered medium with $113.1 \mathrm{mM} \mathrm{NaCl}, 3 \mathrm{mM} \mathrm{KCl}, 7.5 \mathrm{mM} \mathrm{CaCl} 2,11 \mathrm{mM}$ glucose, $20 \mathrm{mM}$ Tris, $2 \mathrm{mM}$ caffeine, $5 \mathrm{mM}$ sodium pyruvate, and $2 \mathrm{mg} / \mathrm{mL} \mathrm{BSA}$ ) in a group of 25-30 oocytes. Fresh semen obtained from boars were mixed with semen extender and stored at $17^{\circ} \mathrm{C}$ up to one week. After placing the oocytes in fertilization medium, $1 \mathrm{~mL}$ semen was diluted by adding $9 \mathrm{~mL}$ DPBS supplemented with $0.1 \%$ BSA, and then washed at $720 \times \mathrm{g}$ for $3 \mathrm{~min}$ by centrifugation. 
After 3 washing steps, the sperm pellet was resuspended with fertilization medium, and $50 \mu \mathrm{L}$ of the resuspension was added to the droplet containing oocytes. The final concentration of sperm in the droplet was approximately $0.25 \times 10^{6} / \mathrm{mL}$. Oocytes and sperms were coincubated in the fertilization medium at $38.5^{\circ} \mathrm{C}, 5 \% \mathrm{CO}_{2}$ for $5 \mathrm{~h}$, then moved to culture droplets containing PZM3 medium (Yoshioka et al., 2002) and incubated at $38.5^{\circ} \mathrm{C}, 5 \% \mathrm{CO}_{2}, 5 \%$ $\mathrm{O}_{2}$.

\section{Genotyping of single blastomeres}

At day 2 after in vitro fertilization, 4-cell stage embryos were collected for genotyping. Embryos were placed in DPBS with $1 \%$ BSA, adjusted to $\mathrm{pH} 1.98$, and gently pipetted a few times to completely remove the zona pellucida and attached sperm. Then, blastomeres were separated into individual cells through repetitive pipetting in DPBS with 1\% BSA. To isolated gDNA, individual blastomere was placed in a PCR tube with $12 \mu \mathrm{L}$ embryo lysis buffer $\left(50 \mathrm{mM} \mathrm{KCl}, 1.5 \mathrm{mM} \mathrm{MgCl}_{2}, 10 \mathrm{mM}\right.$ Tris- $\mathrm{HCl} \mathrm{pH} 8.5,0.5 \%$ Nonidet $\mathrm{P} 40,0.5 \%$ Tween-20, and $200 \mu \mathrm{g} / \mathrm{mL}$ proteinase $\mathrm{K}$ ) and incubated at $65^{\circ} \mathrm{C}$ for 30 min, followed by $95^{\circ} \mathrm{C}$ for $10 \mathrm{~min}$. Target region of TET1 gene was amplified using Dream Tag DNA polymerase (Thermo Fisher Scientific, Waltham, MA, USA). Primers used for PCR amplification are forward: 5'-CTGAGAGAATGCATAGGAAAAAGACTGACTTCCAG-3' and reverse: 5' -GTCCTATCCAAATTCATTCGTGCTGCTCC-3'. Thermocycling conditions were as follows: $95^{\circ} \mathrm{C}$ for $2 \mathrm{~min}$; followed by 39 cycles of $95^{\circ} \mathrm{C}$ for $30 \mathrm{~s}, 55^{\circ} \mathrm{C}$ for $30 \mathrm{~s}$, and $72^{\circ} \mathrm{C}$ for 30 s; $72^{\circ} \mathrm{C}$ for $5 \mathrm{~min}$, and storage at $4^{\circ} \mathrm{C}$. Amplicons were visualized using $2 \%$ gel electrophoresis, then purified using a

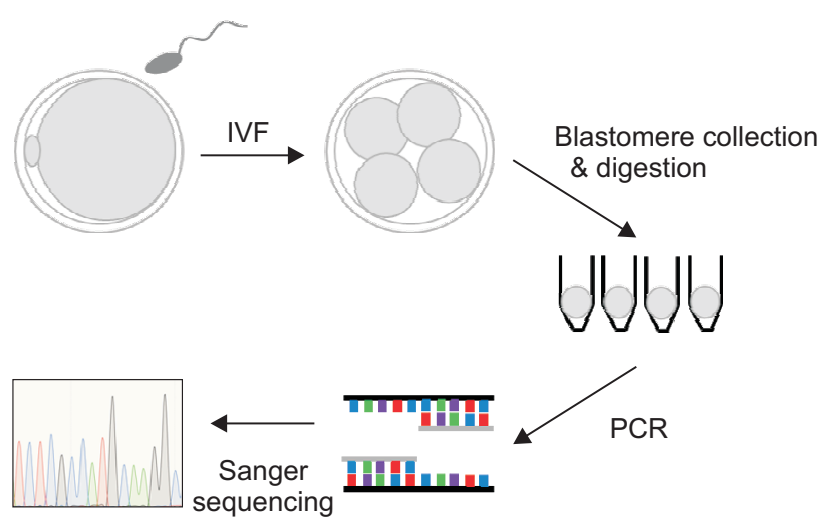

Fig. 1. Schematic diagram of the approach for genotyping of single blastomere in 4-cell embryos.
PCR purification kit (Thermo Fisher Scientific, Waltham, MA, USA) and used for Sanger sequencing. Schematic summary of the genotyping approach is depicted in Fig. 1.

\section{RESULTS}

\section{Successful PCR amplification of a target gene from a single blastomere}

We examined whether PCR amplification from a small amount gDNA is feasible. Similar to our previous study (Uh et al., 2020), a region of TET1 gene was successfully amplified from a single blastocyst (Fig. 2). Sensitivity of the PCR amplification was high enough to amplify the TET1 region from a single 4-cell stage embryo, i.e. four copies of genomic DNA. To examine the feasibility of amplifying the target region from a single blastomere, 4 blastomeres were separated from a 4-cell stage embryo. Genomic DNAs derived from the individual blastomeres were used for PCR, and target region was successfully amplified from the blastomeres. This result indicates that a single copy DNA in a single blastomere of a 4-cell stage embryo gDNA is sufficient to amplify a target genomic region through conventional PCR approach.

\section{Genotyping of single blastomeres from a 4-cell stage embryo}

The PCR amplicons obtained from the whole 4-cell stage embryo and the single blastomeres of the 4-cell embryo were purified and sequenced to verify whether the quantity and quality of the amplified DNA are appropriate for genotyping. Sequencing result of the whole 4-cell embryo showed clear single peaks in the all nucleotide sequences of the target region in chromatogram (Fig. 3A and $3 \mathrm{~B})$. Clear single peaks matched to target sequence

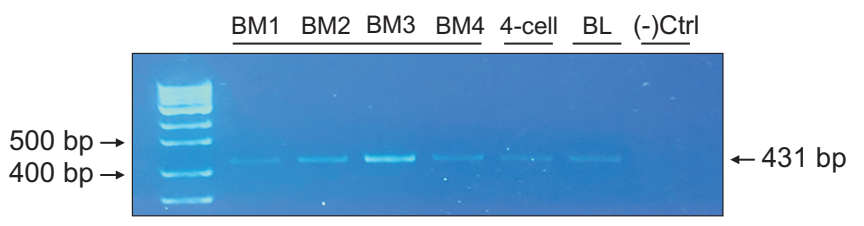

Fig. 2. Gel-electrophoresis image of TET1 gene that PCR amplified from embryonic DNA. The size of amplified region of wild-type TET1 gene is $431 \mathrm{bp}$. The first lane is a size marker. The target regions were successfully amplified from single blastomeres (lane 2-5) of a 4-cell embryo. The four blastomeres were isolated from an identical 4-cell embryo. The target region was also amplified in a whole 4-cell embryo (lane 6) and blastocyst (lane 7). BM, blastomere; $\mathrm{BL}$, blastocyst. 

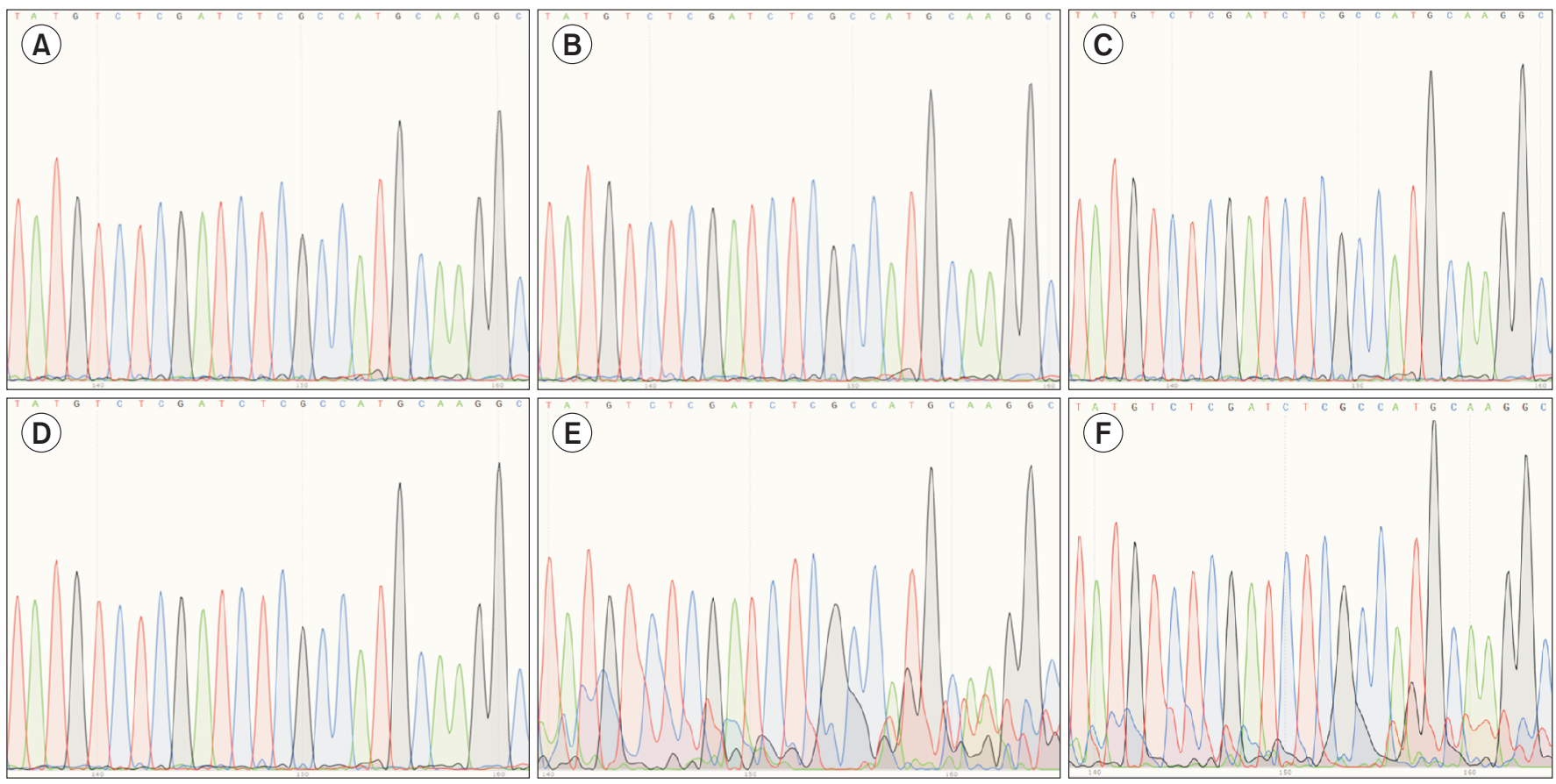

Fig. 3. Sequencing reading of TET1 gene from a whole 4-cell embryo and single blastomeres of a 4-cell embryo. (A) and (B): Clear sequence reading from two individual embryos at 4-cell stage. (C) and (D): Clear sequence reading from two individual blastomeres of a 4-cell stage embryo. (E) and (F): Major chromatogram peaks were completely matched to TET1 gene sequence although there were some baseline noises.

of TET1 gene were also observed in Sanger sequencing of two blastomeres of the 4-cell embryo (Fig. 3C and 3D). In sequencing of other two blastomeres, there were some baseline noise, but major peaks were completely matched to the target sequence (Fig. 3E and 3F). This result suggests that mutation types generated by introducing CRIS$\mathrm{PR} / \mathrm{Cas} 9$ into zygotes can be determined in early stage embryos. The approach of this study could promote the efficiency of producing genetically engineered animals by detecting mosaicism in relatively early stage of preimplantation development.

\section{DISCUSSION}

Prevalence of mosaic genotype is one of the major disadvantages to utilize direct injection of CRISPR/Cas9 system into developing embryos because animals carrying mosaic genotypes often interfere with phenotyping and breeding the founder animals (Lei et al., 2016; Park et al., 2017). Developing an effective approach to detect the frequency of mosaicism assist us to design and optimize CRISPR/Cas9 systems that introduce mosaicism at minimal level. In this study, we successfully genotyped a single blastomere from porcine 4-cell stage embryos, demon- strating that it is possible to perform genomic PCR on a single copy of genomic DNA. We propose that PCR-based genotyping of single blastomere is an efficient approach to identify genomic-modifications in early stage embryos after direct injection of CRISPR/Cas9 system into presumable zygotes.

Previous reports suggest that microinjection timing (Sato et al., 2018) and CRISPR/Cas9 concentration (Tanihara et al., 2019) can influence the frequency of mosaicism in CRISPR/Cas9 injected embryos. For example, microinjection of CRISPR/Cas9 into germinal vesicle-stage oocytes appears to produce non-mosaic transgenic embryos (monoallelic knockouts) (Su et al., 2019). Another study identified optimal microinjection conditions in terms of CRISPR/Cas9 concentration and type, injection time, and embryos (Liu et al., 2016). Rapidly detecting the frequency of mosaicism at a low cost can assist in developing conditions that result in low mosaicism in porcine embryos. For instance, we can select an optimal microinjection timing that minimizes mosaicism. Normally, in vitro matured oocytes are incubated with washed sperm in microdroplets for $6 \mathrm{~h}$ to induce in vitro fertilization. The time point at which sperm enters the oocyte varies for each zygote, with a potential difference of up to $6 \mathrm{~h}$. Comparing the 
frequency of mosaicism after injecting CRISPR/Cas9 system at various time points during/after IVF system should help us identify a timing that can minimize the prevalence of mosaicism. Similarly, different source of Cas9 mRNA/ protein can be examined for their capability to introduce mosaicism.

Unlike whole genome sequencing approach, our PCRbased detection of mosaicism is simple and can deliver the frequency of mosaicism in just a few days. Although detecting mosaicism using whole genome sequencing offers an extensive snapshot of possible alleles in embryos or animals, the method requires library preparation and bioinformatic analysis of sequencing information, which can take months. Alternatively, our PCR-based approach does not require specific equipment or expertise to detect mosaicism and ability to identify mosaicism after CRISPR/ Cas9 injection can be comparable to the whole genome sequencing. Due to the lack of knockout embryos at the time of this study, no targeted event has been detected using the approach. However, our system should be instantly applied to embryos carrying targeted modifications.

In conclusion, we demonstrated that Sanger sequencing of PCR amplicons obtained from single blastomere DNA in 4-cell stage embryo is a feasible method for genotyping of mammalian embryos. Our technique opens the doors to future research that can determine optimal microinjection conditions for minimizing or eliminating mosaicism, therefore, improving the use of CRISPR/Cas9-mediated genome modification in mammalian embryos.

\section{CONFLICTS OF INTEREST}

No potential conflict of interest relevant to this article was reported.

\section{ACKNOWLEDGEMENTS}

This work was supported by fund of Chungnam National University

\section{AUTHOR CONTRIBUTIONS}

JC and KL designed experiments and wrote the manuscript. JC, KU, JR, XF, and SB performed experiment and data analysis. KL supervised the work. All authors read and approved the manuscript.

\section{AUTHOR'S POSITION AND ORCID NO.}

J Cho, Visiting Professor, https://orcid.org/0000-0002-8431-0457

$\mathrm{K}$ Uh, PhD Candidate, https://orcid.org/0000-0001-8893-1034

J Ryu, PhD Candidate, https://orcid.org/0000-0001-8064-5762

$\mathrm{X}$ Fang, PhD Candidate, https://orcid.org/0000-0001-8714-0679

S Bang, MS Student, https://orcid.org/0000-0002-2513-4887

K Lee, Associate Professor,

https://orcid.org/0000-0003-1548-0513

\section{REFERENCES}

Carter DB, Lai L, Park KW, Samuel M, Lattimer JC, Jordan KR, Estes DM, Besch-Williford C, Prather RS. 2002. Phenotyping of transgenic cloned piglets. Cloning Stem Cells 4:131-145.

Cho B, Kim SJ, Lee EJ, Ahn SM, Lee JS, Ji DY, Lee K, Kang JT. 2018a. Generation of insulin-deficient piglets by disrupting INS gene using CRISPR/Cas9 system. Transgenic Res. 27:289-300.

Cho B, Kim SJ, Lee EJ, Ahn SM, Lee JS, Ji DY, Lee SH, Kang JT. 2018b. Production of cloned pigs derived from double gene knockout cells using CRISPR/Cas9 system and MACs-based enrichment system. J. Emb. Trans. 33:245-254.

Choi K, Shim J, Ko N, Eom H, Kim J, Lee JW, Jin DI, Kim H. 2017. Production of heterozygous alpha 1,3-galactosyltransferase (GGTA1) knock-out transgenic miniature pigs expressing human CD39. Transgenic Res. 26:209-224.

Choi KH and Lee CK. 2019. Pig pluripotent stem cells as a candidate for biomedical application. J. Anim. Reprod. Biotechnol. 34:139-147.

Dai Y, Vaught TD, Boone J, Chen SH, Phelps CJ, Ball S, Monahan JA, Jobst PM, McCreath KJ, Lamborn AE, Cowell-Lucero JL, Wells KD, Colman A, Polejaeva IA, Ayares DL. 2002. Targeted disruption of the alphal,3-galactosyltransferase gene in cloned pigs. Nat. Biotechnol. 20:251-255.

García-Tuñón I, Vuelta E, Lozano L, Herrero M, Méndez L, Palomero-Hernandez J, Pérez-Caro M, Pérez-García J, González-Sarmiento R, Sánchez-Martín M. 2020. Establishment of a conditional Nomol mouse model by CRISPR/Cas9 technology. Mol. Biol. Rep. 47:1381-1391.

Hauschild J, Petersen B, Santiago Y, Queisser AL, Carnwath JW, Lucas-Hahn A, Zhang L, Meng X, Gregory PD, Schwinzer R, Cost GJ, Niemann H. 2011. Efficient generation of a biallelic knockout in pigs using zinc-finger nucleases. Proc. Natl. Acad. Sci. U. S. A. 108:12013-12017.

Hirata M, Tanihara F, Wittayarat M, Hirano T, Nguyen NT, Le QA, Namula Z, Nii M, Otoi T. 2019. Genome mutation after 
introduction of the gene editing by electroporation of Cas9 protein (GEEP) system in matured oocytes and putative zygotes. In Vitro Cell. Dev. Biol. Anim. 55:237-242.

Jeon R and Rho GJ. 2020. Porcine somatic cell nuclear transfer using telomerase reverse transcriptase-transfected mesenchymal stem cells reduces apoptosis induced by replicative senescence. J. Anim. Reprod. Biotechnol. 35:215-222.

Ji SJ, Lee G, Park SH, Kim KW, Byun SJ, Ock SA, Hwang S, Woo JS, Oh KB. 2017. Reproductive characteristic of transgenic Massachusetts General Hospital miniature pigs for Xenotransplantation. J. Emb. Trans. 32:165-170.

Lai L, Kolber-Simonds D, Park KW, Cheong HT, Greenstein JL, Im GS, Samuel M, Bonk A, Rieke A, Day BN, Murphy CN, Carter DB, Hawley RJ, Prather RS. 2002. Production of alpha-1,3-galactosyltransferase knockout pigs by nuclear transfer cloning. Science 295:1089-1092.

Lee G, Park SH, Lee H, Ji SJ, Lee JY, Byun SJ, Hwang S, Kim KW, Ock SA, Oh KB. 2017. Development of $\alpha 1$,3-galactosyltransferase inactivated and human membrane cofactor protein expressing homozygous transgenic pigs for xenotransplantation. J. Emb. Trans. 32:73-79.

Lee GS, Kim HS, Lee SH, Kim DY, Seo KM, Hyun SH, Kang SK, Lee BC, Hwang WS. 2005. Successful surgical correction of anal atresia in a transgenic cloned piglet. J. Vet. Sci. 6:243245.

Lei S, Ryu J, Wen K, Twitchell E, Bui T, Ramesh A, Weiss M, Li G, Samuel H, Clark-Deener S, Jiang X, Lee K, Yuan L. 2016. Increased and prolonged human norovirus infection in RAG2/ IL2RG deficient gnotobiotic pigs with severe combined immunodeficiency. Sci. Rep. 6:25222.

Liu S, Liu X, Huang H, Liu Q, Su X, Zhu P, Li H, Cui K, Xie B, Shi D. 2016. Factors affecting efficiency of introducing foreign DNA and RNA into parthenogenetic or in vitro-fertilized porcine eggs by cytoplasmic microinjection. In Vitro Cell. Dev. Biol. Anim. 52:713-722.

Lutz AJ, Li P, Estrada JL, Sidner RA, Chihara RK, Downey SM, Burlak C, Wang ZY, Reyes LM, Ivary B, Yin F, Blankenship RL, Paris LL, Tector AJ. 2013. Double knockout pigs deficient in N-glycolylneuraminic acid and galactose $\alpha$-1,3-galactose reduce the humoral barrier to xenotransplantation. Xenotransplantation 20:27-35.

Ma T, Tao J, Yang M, He C, Tian X, Zhang X, Zhang J, Deng S, Feng J, Zhang Z, Wang J, Ji P, Song Y, He P, Han H, Fu J, Lian
Z, Liu G. 2017. An AANAT/ASMT transgenic animal model constructed with CRISPR/Cas9 system serving as the mammary gland bioreactor to produce melatonin-enriched milk in sheep. J. Pineal Res. 63:e12406.

Park KE, Kaucher AV, Powell A, Waqas MS, Sandmaier SE, Oatley MJ, Park CH, Tibary A, Donovan DM, Blomberg LA, Lillico SG, Whitelaw CB, Mileham A, Telugu BP, Oatley JM. 2017. Generation of germline ablated male pigs by CRISPR/ Cas9 editing of the NANOS2 gene. Sci. Rep. 7:40176.

Piedrahita JA, Mir B, Dindot S, Walker S. 2004. Somatic cell cloning: the ultimate form of nuclear reprogramming? J. Am. Soc. Nephrol. 15:1140-1144.

Ryu J and Lee K. 2017. CRISPR/Cas9-mediated gene targeting during embryogenesis in swine. Methods Mol. Biol. 1605:231-244.

Sander JD and Joung JK. 2014. CRISPR-Cas systems for editing, regulating and targeting genomes. Nat. Biotechnol. 32:347355.

Sato M, Kosuke M, Koriyama M, Inada E, Saitoh I, Ohtsuka M, Nakamura S, Sakurai T, Watanabe S, Miyoshi K. 2018. Timing of CRISPR/Cas9-related mRNA microinjection after activation as an important factor affecting genome editing efficiency in porcine oocytes. Theriogenology 108:29-38.

Su X, Chen W, Cai Q, Liang P, Chen Y, Cong P, Huang J. 2019. Production of non-mosaic genome edited porcine embryos by injection of CRISPR/Cas9 into germinal vesicle oocytes. J. Genet. Genomics 46:335-342.

Tanihara F, Hirata M, Nguyen NT, LE QA, Hirano T, Otoi T. 2019. Effects of concentration of CRISPR/Cas9 components on genetic mosaicism in cytoplasmic microinjected porcine embryos. J. Reprod. Dev. 65:209-214.

Tian H, Luo J, Zhang Z, Wu J, Zhang T, Busato S, Huang L, Song N, Bionaz M. 2018. CRISPR/Cas9-mediated stearoyl-CoA desaturase 1 (SCD1) deficiency affects fatty acid metabolism in goat mammary epithelial cells. J. Agric. Food Chem. 66:10041-10052.

Uh K, Ryu J, Farrell K, Wax N, Lee K. 2020. TET family regulates the embryonic pluripotency of porcine preimplantation embryos by maintaining the DNA methylation level of NANOG. Epigenetics 15:1228-1242.

Yoshioka K, Suzuki C, Tanaka A, Anas IM, Iwamura S. 2002. Birth of piglets derived from porcine zygotes cultured in a chemically defined medium. Biol. Reprod. 66:112-119. 